\title{
Boosting diabetes and pre-diabetes screening in rural Ghana
}

\section{[version 1; peer review: 1 approved with reservations, 1 not}

\section{approved]}

\author{
Bernard Effah Nyarko (iD, Rosemary Serwah Amoah, Alessandro Crimi (ii)
}

African Institute for Mathematical Science, Cape Coast, Ghana, Ghana

V1 First published: 14 Mar 2019, 8:289

https://doi.org/10.12688/f1000research.18497.1

Latest published: 27 Aug 2019, 8:289

https://doi.org/10.12688/f1000research.18497.2

\section{Abstract}

Background: Diabetes is a growing worldwide disease with serious consequences to health and with a high financial burden. Ghana is one of the developing African countries where the prevalence of diabetes is increasing. Moreover, many cases remain undiagnosed, when along with pre-diabetic cases they can be easily detected. Prediabetes condition occurs when blood sugar levels are higher than normal but are not high enough to be classified as diabetes, and it is still reversible.

The main objective of this study is to propose a novel method to increase diabetes and pre-diabetes early detection in rural areas. A secondary aim is to look for new related behavioral determinants specific to rural Ghana, by comparing subjects at risk with those already diagnosed as diabetic.

Methods: The screening approach was based on tests performed proactively by community nurses using glucometers and mobile phone apps. As a pilot for future policies, glycemic tests were carried out on 101 subjects from rural communities in Ghana deemed at risk and unaware of their diabetic/pre-diabetic status. A comparison of dietary and lifestyle habits of the screened people was conducted in regards to a cohort of 103 diabetic patients from the same rural communities. Results: The pilot screening detected 2 diabetic subjects ( $2 \%$ of the cohort) showing WHO diabetic glycemic values, and 20 pre-diabetic subjects (19.8\% of the cohort) which showed the effectiveness of the user-friendly approach. The need for further campaigns on alcohol consumption and physical activity has emerged, even in rural areas. Conclusions: Policies based on prevention screening as reported in the manuscript have the potential to reduce diabetes incidence, if actions are taken while patients are pre-diabetic, reduce complication related to late diagnosis and indirectly related health-care costs in the country.

Open Peer Review
Approval Status
version 1
14 Mar 2019
(revision)
1. Juan Salazar (iD), University of Zulia,
Maracaibo, Venezuela
2. Frank Peter Schelp
University, Khon Kaen, Thailand
Any reports and responses or comments on the
article can be found at the end of the article.

Page 1 of 18 
Keywords

diabetes, mHealth, community health workers, pre-diabetes, Ghana,

rural health

\section{Corresponding author: Alessandro Crimi (alecrimi@alice.it)}

Author roles: Effah Nyarko B: Data Curation, Formal Analysis, Investigation, Methodology, Writing - Original Draft Preparation; Amoah RS: Data Curation, Formal Analysis, Investigation, Methodology, Writing - Original Draft Preparation; Crimi A: Conceptualization, Project Administration, Supervision, Writing - Review \& Editing

Competing interests: No competing interests were disclosed.

Grant information: This study was partially funded by the Regional Registry for Internet Number Resources serving the African Internet Community (Afrinic).

The funders had no role in study design, data collection and analysis, decision to publish, or preparation of the manuscript.

Copyright: ( 2019 Effah Nyarko B et al. This is an open access article distributed under the terms of the Creative Commons Attribution License, which permits unrestricted use, distribution, and reproduction in any medium, provided the original work is properly cited.

How to cite this article: Effah Nyarko B, Amoah RS and Crimi A. Boosting diabetes and pre-diabetes screening in rural Ghana [version 1; peer review: 1 approved with reservations, 1 not approved] F1000Research 2019, 8:289

https://doi.org/10.12688/f1000research.18497.1

First published: 14 Mar 2019, 8:289 https://doi.org/10.12688/f1000research.18497.1 


\section{List of abbreviations}

IDF International Diabetes Federation

WHO World Health Organization

CHPS Community-based health planning and services

BMI body mass index

CDP confirmed diabetic participants

USP unknown diabetic status participant

\section{Introduction}

Diabetes is one of the fastest growing non-communicable killer diseases in the world, claiming one life every eight seconds and a limb every 30 seconds $^{1}$. Diabetes of all types can lead to complication in many parts of the body and can increase the overall risk of dying prematurely ${ }^{2-7}$. Pre-diabetes condition occurs when blood sugar levels are higher than normal, but are not high enough to be classified as diabetes; this often has no symptoms, and is reversible ${ }^{3}$.

According to the latest 2016 data from the World Health Organization (WHO), amongst adults living with diabetes melilites, $80 \%$ live in low and middle-income countries such as those in the Asia and Eastern Pacific region. The largest number has been reported in China ( 90 million people ${ }^{6}$ ), followed by India (61.3 million people) and Bangladesh (8.4 million people $)^{5}$. Complications of diabetes results in increased morbidity, disability, and mortality and have a high economic cost, especially in developing countries ${ }^{8}$. More specifically, the reported prevalence of type 2 diabetes ranges from $1 \%$ in rural Uganda to $12 \%$ in urban Kenya. While gestational diabetes has been reported in Sub-Saharan countries at varying levels (e.g. from $0 \%$ in Tanzania to $9 \%$ in Ethiopia ${ }^{9}$ ). Lastly, even considering those values an underestimate, it is expected that the reported cases will reach 82 million by the $2030^{10}$.

Ghana is challenged with the increasing prevalence of diabetes, similar to other African countries, with a prevalence of $3.6 \%$ in adults and 518,000 diagnosed cases within the country ${ }^{11}$. More specifically, The prevalence of diabetes in some parts of Ghana has been found to be higher than the world average of $6.4 \%{ }^{12,13}$. Moreover, the 2015 report of the IDF indicated many other cases probably remain undiagnosed, posing an increased danger of complications for people living with diabetes unaware of the consequences. Previous studies in the country showed that low level of physical activity and obesity were associated with increased risk of diabetes ${ }^{4}$. Additionally, old age and level of education were also associated with increased risk of diabetes ${ }^{4}$. It has also been observed that within Ghana sugary drinks consumption is linked to type 2 diabetes ${ }^{14}$. Community-based health planning and services (CHPS) is a national health program in Ghana adopted in 1999 to reduce geographical barriers to health care access ${ }^{15}$. According to the CHPS policy, relocating nurses directly to communities could outperform an entire sub-district health center. The cost-effectiveness of CHPS for malaria, diarrhea, and pneumonia has been recently reported $^{16}$. However, specific interventions for non-communicable diseases such as diabetes have not yet been investigated within the CHPS policy.

Vulnerable populations such as those in low- and middleincome countries are generally more affected by diabetes related complications ${ }^{17}$. As in several fields of healthcare, mobile health (mHealth) has the potential of reducing for vulnerable populations with diabetes ${ }^{18}$. This can occur either by sending reminders or by increasing access to patient management ${ }^{19}$. Despite the plethora of studies on mHealth and diabetes management ${ }^{19-21}$, no study has been carried out in rural Africa with the aim of improving detection of diabetes and pre-diabetes by using mobile technologies and community nurses.

This study proposes a novel screening approach based on community nurses using glucometers and mobile phones, performing tests on undiagnosed and diagnosed subjects proactively within the community without waiting for participants to present at the clinic. The main objective is to develop a novel method to increase diabetes and pre-diabetes detection, and to find new behavioral determinants related to those conditions. In particular, the purpose of the mobile app is to simplify the tracking operations of the nurses and to collate the data into a centralized secure server. For this purpose, a pilot project was carried out in rural communities of the Central Region of Ghana to assess the feasibility of the approach. A secondary objective was to look for new behavioral determinants related to the rural Ghanaian populations by carrying out a comparison with a group of subjects diagnosed with diabetes from the same communities. Similar to a project carried out in the same area about improving prenatal care $^{22}$, the project utilized community nurses instead of the participants to assure reliable glucose level data collection.

\section{Methods}

Study design

We performed a community-based cross-sectional study using mixed methods of quantitative and qualitative analysis.

Data were collected by community nurses by using a mobile phone application and sent to a secure database. The inclusion criteria for the participants were that they were members of the study communities, the exclusion criteria included being $<18$ years and having a prior diagnosis of diabetes of any type. A proportional comparison group with diabetes was also recruited, with the aim of possibly finding common dietary habits with the screened subjects found to be diabetic/pre-diabetics in both groups. The inclusion criteria for the comparison group were having a prior diagnosis of type 2 diabetes, being part of the rural communities sampled, and being older than 18 years. To avoid unnecessary overtime for the nurses, we excluded children and young adults under the age of 18 years; we acknowledge this as limitation for our study.

Subjects were assessed as "non-diabetic" according to their diabetes status awareness, obtained by the following question: "Has a doctor or another health professional ever diagnosed you have diabetes?" Further variables analyzed were: family history 
(family member diagnosed with diabetes); pregnancy; history of hypertension; screened glucose level; lifestyle characteristics (going to sleep within 1 hour after dinner and level of physical activities); body mass index (BMI), and diet (consumption per typical week of dishes based on staple or maize/corn, root and tuber-potatoes/cassava, and alcohol). Those variables are further described in the following sections as whether they were assessed by the nurses or self-reported.

\section{Data source}

The research was conducted in the central region of Ghana, specifically within the Biriwa and Anomabo communities. These two communities are in the Mfantsiman Municipal District and based on the 2010 census, the two towns have a population of about 7,500 and 14,389 respectively. Those communities have been chosen due to them being relatively close to a main road connecting urban centers. The assumption is that the members of those communities are more prone to adopt unhealthy habits (such as smoking and drinking) which are more common in urban centers.

Community nurses from rural clinics were instructed to visit rural communities performing glucose screening, when fasted if possible or alternatively at random. Those tested were subjects known to have diabetes, subjects deemed at risk or those willing to be tested. A total of 204 people were tested in a window period of 6 months (from June to December 2017). This sample size was reached following the minimum sample size for the study given by two populations of $n=86$ subjects. This minimum sample size was computed by using the GPower software version 3.1 for an a priori two-tail t-test with alpha $=0.05$, effect size 0.5 and power 0.90 . The quantified sample size also matches constraints according to logistics related to the community nurses. Indeed, the aim was for the proposed screening to be performed by the nurses in addition to their normal activities without resulting in the need for overtime or compromising the other activities were carrying out. As one community nurse per community was used, in this pilot two nurses were employed.

The nurses were equipped with glucometers and low-cost Android smart phones. They received a short (less than one day) training on the app and were supported on its use during the first week of the project. Data were stored through the mobile phone app and sent to a server to improve management and facilitate eventual longitudinal screening. The developed app was based on the CommcareHQ framework, and comprised a series of guided questions that the nurses completed in addition to the glucose test (questions used are available as Extended data ${ }^{23}$ ). Some screen-shots of those questions are depicted in Figure 1. If network was not available at the point of data collection, information could be sent later when the network was available. CommcareHQ is a popular mobile data collection, and it has been used in several projects. For a review on projects using the CommcareHQ platform, the reader is addressed to 24 .

Figure 2 shows the typical two steps of the screening, first a nurse is performing a glucose test (on the left), and then the data are recorded through the app (on the right). Collected data from respondents were from the rural communities, both male and female, including pregnant women with the intent of capturing eventual gestational diabetes case $^{25}$. The sampling of

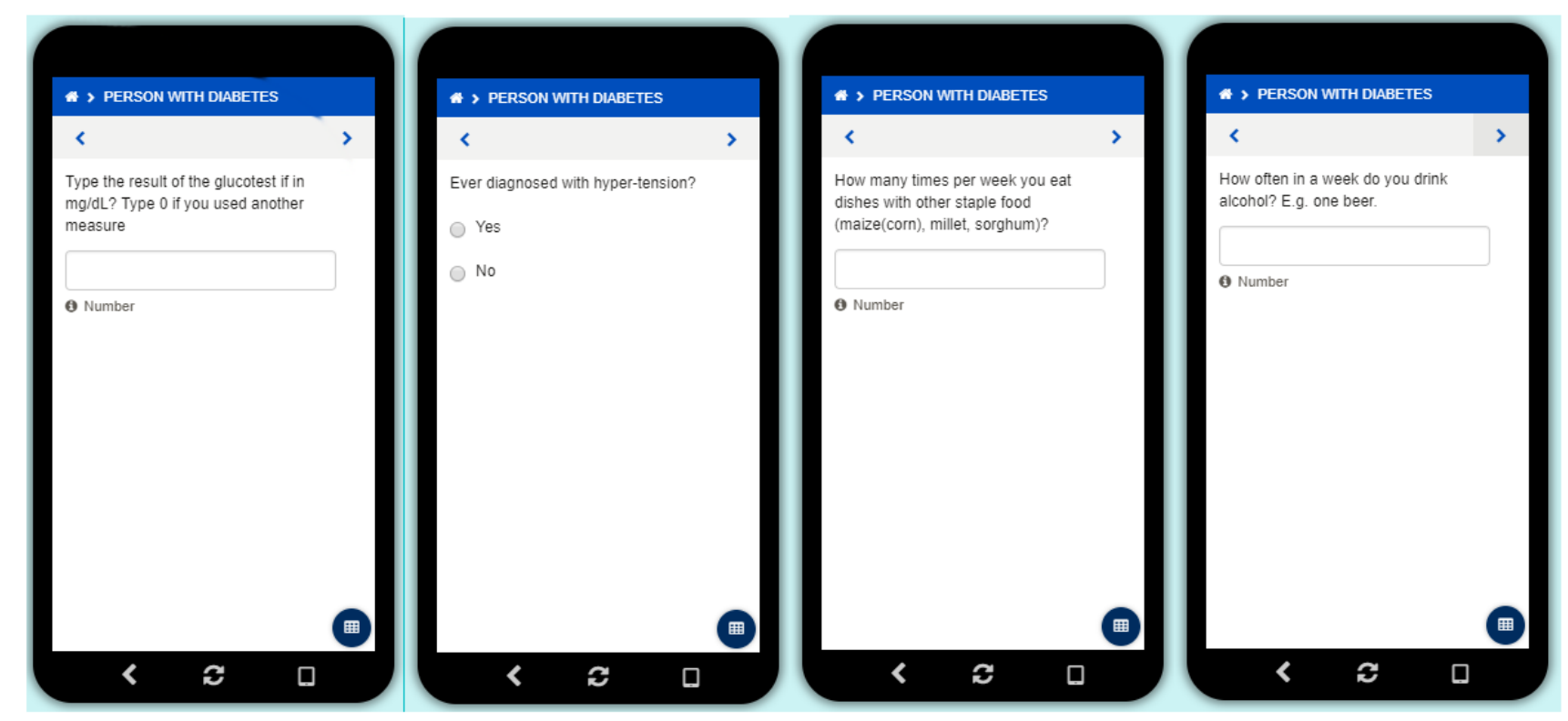

Figure 1. Screen-shots showing some of the guided questions the community nurse were completing while performing the glucose tests. The questions related to diet were based on general consumption for a typical week and not the week at point of sampling. 

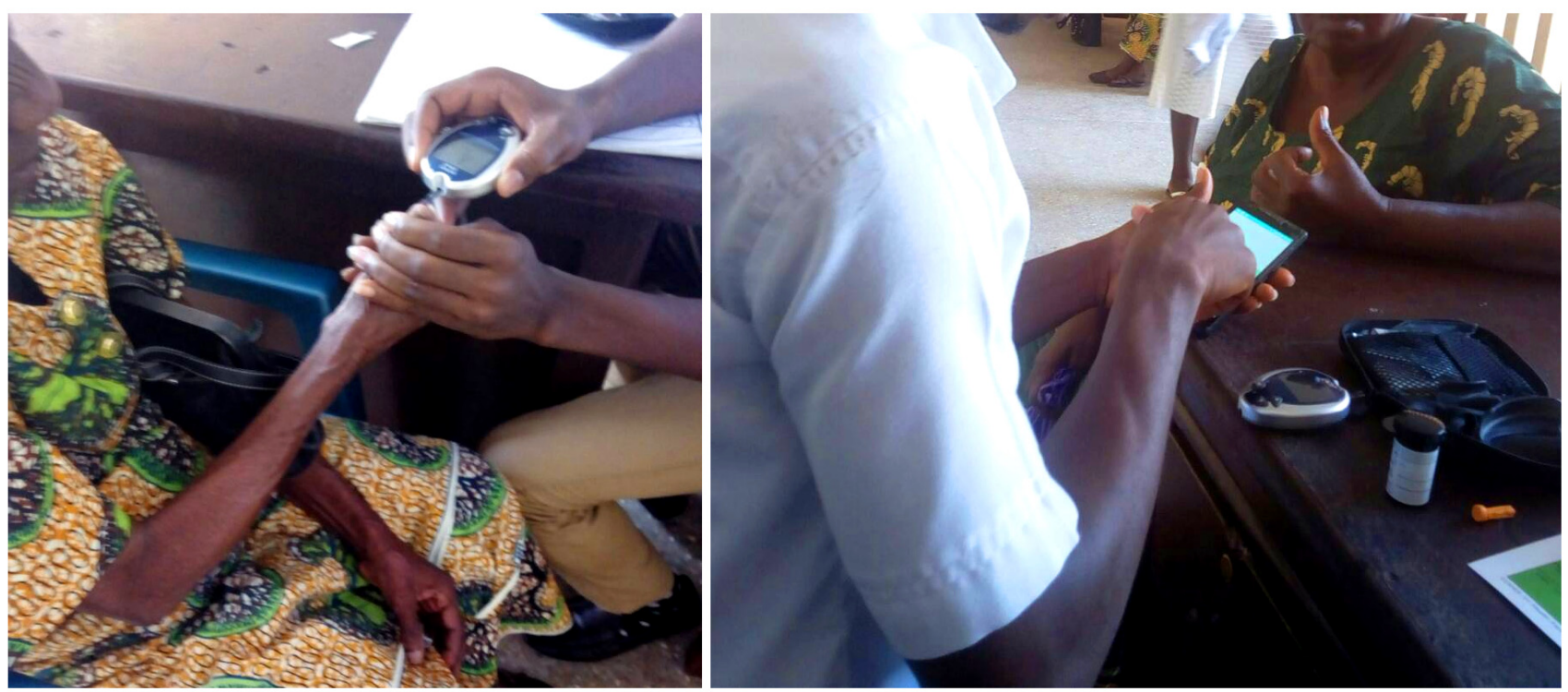

Figure 2. A typical two steps screening, first a nurse is performing a glucose test (on the left), and then the data are recorded through the app (on the right).

candidates at risk was based on physical factors and at the nurse's discretion. During regular visits to the rural communities the nurses assessed whether the person to be tested was a potential diabetic candidate and therefore deemed to be tested (e.g. appearing overweight), paying particular attention to pregnant women. By doing this we have introduced a piloted bias (as overweight people, pregnant women and other cases were deemed at risk by the nurses). Therefore, with those biases, the resulting statistics is not representative of a random screening of the national population.

Nevertheless, our focus is not to estimate total incidence of undetected diabetes or pre-diabetes, but to propose an approach that can detect as many as possible cases which otherwise would go unnoticed.

However, to avoid a strong bias individual deemed healthy that were willing to be tested were included. Any detected diabetic or pre-diabetic cases were immediately informed, and lifestyle changes or pharmaceutical therapies discussed. Data were collected on known diabetic patients as well, to evaluate the differences or similarities in lifestyle among the various groups.

With the mobile phone app, the community nurses could also keep track of longitudinal changes or whether a subject has been already tested, in a similar manner of a project conducted in the same area about boosting prenatal care ${ }^{22}$. Subjects who came into contact with community nurses were asked the last time they had a meal and based on the response blood glucose measurements were classed as either fasting blood sugar levels or random blood sugar levels. Furthermore, the following information were recorded from the subject a) Anthropometric indices (weight, height, BMI) measured by the nurses b) Demographic Information (sex, age) self-reported c) Blood glucose measurement (fasting or random sugar test) measured by the nurses d) Information on risk factors (pregnancy, family history of diabetes, history of hypertension, kidney disorder, alcoholism, low levels of exercise and unhealthy eating habits) selfreported. OneTouch Ultra (Milpitas, CA, USA) and Accu-Check (Hoffmann-La Roche SA, Basel, Switzerland) strips and glucometers were used to measure the blood glucose level. According to the WHO classification ${ }^{26}$, a fasting blood glucose level greater $110 \mathrm{mg} / \mathrm{dL}$ but less than $126 \mathrm{mg} / \mathrm{dL}$ was considered pre-diabetic. A fasting blood sugar level $126 \mathrm{mg} / \mathrm{dL}$ or above was considered diabetic. A random blood sugar level greater $140 \mathrm{mg} / \mathrm{dL}$ but less $200 \mathrm{mg} / \mathrm{dL}$ was considered pre-diabetic. Above $200 \mathrm{mg} / \mathrm{dL}$ was considered diabetic. Family history of diabetes is referred to occurrence of diabetes in close relatives defined as either father, mother, siblings or offspring. Most of the data were assessed by the nurse though some were self-reported by the subjects and this might represent a limitation. The data entered through the developed Android app were stored in a secure server provided by Dimagi. Data were entered in the forms of the mobile app and transmitted, encrypted, to the cloud-based server, where they were accessed and downloaded via a password-protected web interface.

\section{Analytical approach}

The main aim of the study was to determine if it is possible to easily detect diabetic and pre-diabetic subjects through community nurses already involved and active within the CHPS policy. Additionally, dietary habits and demographic information were 
collected by the community nurses along with glucose level to explore novel determinants related to the disease, which have not been reported in literature so far.

The data entered through the mobile phone app were downloaded and analyzed by $\mathrm{R}$ computing software version 3.5.2. Quality check on the data was performed and forms deemed clearly erroneous were removed. Statistically significant relationships among the collected information were sought comparing the population at risk and the population with assessed diabetes by using a two-tail t-test, and the related p-value less or equal to 0.05 was considered to indicate a significant value.

The study also took advantage of the screening process to collect further insights through qualitative methods. Hence, the quantitative information was complemented with qualitative data obtained through semi-structured interviews performed by the authors with the community nurses to identify further relevant elements at the end of the pilot project. After revision of notes, the transcripts were typed and coded by using NVivo 10 (QSR International, Melbourne, Australia). The interviews were thus analyzed by using qualitative conventional content analysis. The starting open questions were "what are your general comments about the projects?", "Which shortcomings did you notice?", "What are your suggestions?".

\section{Results}

The diabetes screening saw over 204 inhabitants in Anomabo and Biriwa over a period of 6 months. Of those, 103 were previously confirmed diabetic participant (CDP) with an average age of $62.9 \pm 11.2$ years, and 101 people, with an average age of $30 \pm 9.7$ years, with unknown diabetic status participant (USP). Originally 211 forms were completed, however, 7 of them were deemed erroneous during the quality check and therefore were removed before the analysis. For each person data were collected only once. The CDP cohort comprised 66 female and 37 male subjects, while the USP cohort comprised 95 female and 6 male subjects (see Underlying data ${ }^{23}$ ). Details of the main demographic characteristics revealed for the two groups are reported in Table 1 while the breakdown of the study variables is distributed in the other tables. Community nurses see on average 20 patients per day 5 times a week. Their duties mainly encompass malaria, diarrhea, and pneumonia treatments which are generally perceived as more urgent. During the pilot, the total number of people approached for the diabetes screening was 240 with a participation rate of $88 \%$. The $12 \%$ of who refused the screening reported as the main motivation the unwillingness to sign the written consent for the study.

Two-sample $t$-test performed comparing the BMIs was statistically significant $(\mathrm{P}$ value $<0.05)$ although they were both normoweight. Some subjects of the CDP cohort also presented with co-occurrence of ulcers $(n=4)$, asthma $(n=1)$, arthritis or rheumatism $(n=3)$, and kidney disease $(n=1)$. At time of testing participants in the USP cohort presented with co-occurrence of asthma $(n=4)$, arthritis and rheumatism $(n=1)$, and typhoid fever $(n=1)$. The subject presenting typhoid fever showed a random glucose blood level of $132 \mathrm{mg} / \mathrm{dL}$ which could not be considered neither diabetic nor pre-diabetic. Therefore, typhoid fever was not considered a confounding factor as the tested participant did not show a high value due to this. These results are summarized in Table 2.

\section{Cases detection}

During the proactive screening performed by the community nurses, two subjects (1 female, not pregnant, with hypertension, 35.4 BMI; 1 male, 25.7 BMI) were found to be hyperglycemic at fasting which would diagnose them as diabetic according to the current WHO threshold ${ }^{26}$. These subjects were not aware of their condition despite close relatives with diagnosed

Table 1. Summary of the main demographic characteristics.

\begin{tabular}{|l|l|l|l|}
\hline \multicolumn{1}{|c|}{ Characteristic } & $\begin{array}{c}\text { Absolute number } \\
\text { (weighted proportion) }\end{array}$ & $\begin{array}{c}\text { confirmed diabetic participants } \\
\text { confirmed diabetic (CDP) (weighted } \\
\text { proportion) }\end{array}$ & $\begin{array}{c}\text { Unknown diabetic status participant } \\
\text { (USP) (weighted proportion) }\end{array}$ \\
\hline Total participants & $204(100 \%)$ & $103(50.5 \%)$ & $101(49.5 \%)$ \\
\hline Sex & $38(20 \%)$ & $32(16 \%)$ & $6(4 \%)$ \\
\hline Male & $161(80 \%)$ & $66(33 \%)$ & $95(47 \%)$ \\
\hline Female & & 62.9 & 30 \\
\hline Age & 46.5 & $4(2 \%)$ & $70(34 \%)$ \\
\hline Average & $74(36 \%)$ & $5(3 \%)$ & $26(13 \%)$ \\
\hline Age group 18-30 & $31(16 \%)$ & $94(45 \%)$ & $5(3 \%)$ \\
\hline Age group 31-49 & $99(48 \%)$ & & $77(37.5 \%)$ \\
\hline Age group 50 and beyond & & $32(16 \%)$ & $24(11.5 \%)$ \\
\hline $\begin{array}{l}\text { Geographical area of } \\
\text { residency }\end{array}$ & $148(72.5 \%)$ & & \\
\hline Anomabo & $56(27.5 \%)$ & & \\
\hline Biriwa & & & \\
\hline
\end{tabular}


diabetes (son in one case and siblings in the other). They did not present any further symptoms, and they were not habitual consumers of alcohol or red meat. However, their diet was based on dishes with large amounts of maize corn, cassava and rice.

In total, 20 pre-diabetic cases were identified according to the WHO threshold, four tested at fasting and 16 at random (19 female; 1 male). No hypertension or other symptoms were identified, and 5 of had relatives with diabetes (mother or father). Half of the detected subjects reported consuming red meat almost daily, and all claimed to avoid alcohol consumption. They also reported frequently consuming dishes comprising of maize corn, cassava and rice, averaging respectively 8.5, 8.5 and 3.5 times per week.

All subjects of both groups claimed they were used to performing physical activities due to their daily job. No statistical difference ( $\mathrm{p}$-value $>0.05$ ) across the two cohorts was detected regarding weekly consumption of red meat, maize corn, cassava or rice. The mean consumption of alcohol across the two populations was also not significantly different ( $\mathrm{p}$-value $>0.05$ ), however, in the CDP cohort 14 subjects declared to consume typically at least 1 alcoholic beverage per week (plus 10 claimed to be former alcohol drinkers before their diagnosis and then changed this behavior) while in the USP cohort only 6 participants indicated they consumed at least 1 alcoholic beverage per week. Furthermore, in the CDP cohort 3 subjects claimed to have reduced the consumption of cassava based products, and another 2 for red meat. 88 subjects reported to have drastically reduced the consumption of sugar, salt or both but not to have altered their diet. No case of gestational diabetes was detected. Table 3 reports the mean and standard deviation of the blood glucose level for both cohorts, distinguishing whether tests were fasting or random. Summarizing qualitatively, no specific novel determinant was found.

Qualitative comments from the nurses

The two nurses who performed the screening in the rural areas were asked to give their qualitative opinion at the end of the 6 months pilot. The following are the main extracts of those interviews.

- Enrolled community nurse, Anomabo Health Centre, Anomabo:

"There should be continuous education of the masses on diabetes to create awareness. There should also be financial support from governments, and non-governmental organizations to aid routine check up of known diabetes patients, this will encourage them to always take their medication as regular checking of blood glucose level for free help them to know the progress with their condition."

"Medication as insulin is covered by national insurance but not the needles for the screening, and this can make people refrain from screening."

Table 2. Summary of study variables related to BMI and health conditions. demographic characteristics for the cohort. BMI is reported as means and standard deviations, (co-) occurrence of hypertension or close relative with diabetes, while diseases are reported in absolute values.

\begin{tabular}{|c|c|c|c|}
\hline Study variables & Absolute numbers & $\begin{array}{c}\text { confirmed diabetic } \\
\text { participants (CDP) } \mathbf{n = 1 0 3}\end{array}$ & $\begin{array}{c}\text { Unknown diabetic status } \\
\text { participant (USP) } \mathbf{n = 1 0 1}\end{array}$ \\
\hline BMI & $25.4 \pm 4.9$ & $24.2 \pm 5.1$ & $26.7 \pm 4.6$ \\
\hline Hypertension & $65(32 \%)$ & $63(30.8 \%)$ & $2(1.2 \%)$ \\
\hline Ulcers & 0 & 0 & 0 \\
\hline Close relatives with diabetes & $105(51.5 \%)$ & $72(34.5 \%)$ & $33(17 \%)$ \\
\hline Asthma & $5(3 \%)$ & $1(0.5 \%)$ & $4(2.5 \%)$ \\
\hline arthritis or rheumatism & $4(2.5 \%)$ & $3(2 \%)$ & $1(0.5 \%)$ \\
\hline kidney disease & $1(0.5 \%)$ & $1(0.5 \%)$ & 0 \\
\hline Typhoid fever & 0 & 0 & $1(0.5 \%)$ \\
\hline
\end{tabular}

Table 3. Mean glucose levels with standard deviation for the two groups and the types of screening and the related $p$-value.

\begin{tabular}{|l|l|l|l|}
\hline Cohort/Glucose level & $\begin{array}{l}\text { confirmed diabetic participants } \\
\text { (CDP) } \mathbf{n = 1 0 3}\end{array}$ & $\begin{array}{l}\text { Unknown diabetic status } \\
\text { participant (USP) } \mathbf{n = 1 0 1}\end{array}$ & \begin{tabular}{l}
$\mathbf{p}$-value \\
\hline Fasting
\end{tabular} \\
\hline $160.6 \pm 71.6$ & $103.1 \pm 181$ & $<0.001$ \\
\hline Random & $173.9 \pm 65.4$ & $123.3 \pm 20.6$ & 0.002 \\
\hline
\end{tabular}


- Enrolled community nurse, Boabab Health Clinic, Biriwa:

"Most patients were willing to be tested and ready to give any information on their personal lifestyle, diet and medication. There is a general trust in tests performed by clinical personnel regardless on cultural beliefs and on the fact that we are a small clinic."

"Particularly, female clients above the age of forty were pleased to participate in the screening exercise."

"Furthermore, some clients were not able to provide precise information about their diet and family history."

"Screened people reported performing some kind of sport activity related to their job, believing it was sufficient to keep them healthy."

\section{Discussions}

Mobile phone apps and pro-active screening can help community nurses to spot new cases of diabetes and pre-diabetes. In particular, the proposed approach was based on pro-actively performing blood screening during rural visits of the community nurses, who were collecting information via the mobile phone app. This can also help tracking and monitoring, as the nurses can follow up the status of the participants during future visits.

Our findings indicate that some individuals in vulnerable populations, such as those in rural Ghana, are not aware of becoming diabetic or being in diabetic condition. We report two cases of diabetic participants in the USP cohort (2\%) and 20 as prediabetic $(19.8 \%)$, which we consider to be high when compared to previously reported statistics ${ }^{27}$. However, it must be taken into account that the cohort selection was not purely random, and piloted bias was introduced as the subjects to be tested were chosen according to the nurse's discretion. Therefore, these percentages should not be taken as a representative sample of the national population. The proposed approach aims instead at detecting as many cases as possible of diabetics and prediabetics which otherwise would go unnoticed. For this purpose it proved to be successful, inexpensive and easily integrated into the standard duties of community nurses.

Initially the nurses were equipped with ihealth glucometer dongles for the smartphone (ihealth, Mountain View, CA, USA). The anecdotal comments from nurses were that. despite the initial interest, they were not practical to collect data, though they might be suitable for a single individual. The reason can be related to the familiarity of the nurses to known tools such as Accu-Check and OneTouch, or the cumbersome use of switching continuously between the mobile app of the glucometer dongle and the app to record the data. The use of a mobile app can allow for large institutions to easily monitor diabetes in rural areas through the collected data held in a secure centralized server. Moreover, mobile apps appear more user friendly for the nurse in comparison to cumbersome paperwork.

During the qualitative interviews, one nurse pointed out that despite the marginal costs of glucose tests both patients and government are not promoting them, while it could be costeffective for Ghanaian institutions to detect pre-diabetic cases instead of dealing with a growing diabetic population, as has been shown for similar vulnerable populations ${ }^{28}$. Despite the progresses made in Ghana to achieve universal health access and coverage, financial barriers to diabetes service utilization still exist. Subjects usually do not undergo glucose tests due to financial constraints, as the test is not covered under most standard medical insurance policies, as is the case in Nigeria and Tanzania $^{29}$. One nurse mentioned that subjects were often not able to report their dietary habits and were unaware of the effects of their diet on their health. Conversely to prenatal care ${ }^{30}$, it appears that generally the members of the communities trust the personnel of the clinics for this type of tests.

At population level the CDP and USP cohort were normoweight (having a BMI between 18.5 and 24,99), though there were subjects which were obese and with hypertension in both groups. It is worthwhile to mention that the CDP subjects might have some dietary changes already after being informed of being diabetic, which could have affected their weight and other measurements. However, from the interviews it seems that the major changes were the reduction of consumption of salt and sugar, some increased their consumption of vegetables and fruit, and some reducing the consumption of alcohol beverages. The study did not track behavioral changes, but we can presume that these may have occurred and can represent confounding factor. No statistically significant difference in alcohol consumption between the two groups was detected. However, this could be due to the fact that some individuals in the CDP cohort changed their dietary habits (10 people reported to have cut out alcohol consumption after their diagnosis). Moreover, the nurses were instructed to focus for both groups on women which might consume fewer alcoholic beverages than men. Nevertheless, the general impression of the nurses was that the alcohol consumption had an impact. With the increase in quality of life in the country, western habits such as alcohol consumption might be also increasing, and therefore augmenting the risk of diabetes. It has been noticed that people informed of their condition tend to change their dietary habits. Nevertheless, given the countrywide growing trend in alcohol consumption, social marketing campaign related to this ${ }^{31}$ should be considered.

Almost all subjects of both groups reported to perform regular physical activities related to their job. However, this information seems vague and it is not clear whether this physical activity is aerobic or resistance or whether it is sufficient to keep a healthy glucose level. Most likely further activities should be proposed. Jogging and other sport activities are inexpensive and easy to promote. Therefore, promoting this type of sport activities can address this issue. Moreover, it appears necessary in the future to use more detailed investigations about sport activities, such as using the WHO global physical activity questionnaire ${ }^{32}$.

Ghana has experienced an exponential increase of the mobile network, social media and smartphones in the recent years ${ }^{33}$. Beyond the screening of the population carried out by nurses, smartphones can have an impact on glycemic control, as 
smartphone dongles can be inexpensive and attractive to young users. Strategies such as gamification, and social media should be explored to increase awareness on glycemic levels as shown in other contexts ${ }^{34}$.

\section{Conclusions}

Proactive glycemic screening on vulnerable population - such as those living in rural areas - can be effective in detecting new cases of diabetes and pre-diabetes. Our approach using community nurses screening subjects deemed at risk and collecting data on mobile phone was found to be effective, and suitable for longitudinal studies. Campaigns increasing awareness of alcohol consumption, physical activity, nutrition and healthy habits should be emphasized in any prevention strategy as the population seems to still be unaware of the consequences.

Despite this, studies with larger population are required to confirm the results. The diabetes and pre-diabetes screening described in this manuscript can be easily included into the national CHPS policy with several potential benefits. Those benefits include reducing incidence by detecting cases of prediabetes which hopefully will not convert into type- 2 diabetes and enabling timely treatment of diabetes patients avoiding complications related to delays in treatment.

\section{Ethics and consent}

All procedures performed in studies involving human participants were in accordance with the ethical standards of the institutional and/or national research committee and with the 1964 Helsinki declaration and its later amendments or comparable ethical standards. Written consent for the reported data was collected. The Noguchi Memorial Institute for Medical Research of the University of Ghana recorded the study with the identifier 076/13-14.

\section{Data availability}

Underlying data

Zenodo: DiabetesUP: Initial repository of data related to Nyarko et al. http://doi.org/10.5281/zenodo.258711723

This project contains the following underlying data:

- Diabetes_cohort.xls (Collected data for diabetes cohort)
- Unaware_cohort.xls (Collect data for participants with no prior diagnosis of diabetes)

\section{Extended data}

Zenodo: DiabetesUP: Initial repository of data related to Nyarko et al. http://doi.org/10.5281/zenodo. $2587117^{23}$

This project contains the following extended data:

- Questionnaires.odt (Questions asked by the app)

Data are available under the terms of the Creative Commons Zero "No rights reserved" data waiver (CCO 1.0 Public domain dedication).

\section{Software availability}

The CommCare software is required to use the source code, questions used in the app are available as Extended data

Software available from: https://play.google.com/store/apps/ details?id=org.commcare.dalvik\&hl=en

Source code available from: https://github.com/alecrimi/diabetesUP/tree/v1.0

Archived source code at time of publication: http://doi.org/ 10.5281 /zenodo. $2587117^{23}$

License: Creative Commons Zero "No rights reserved" data waiver

\section{Grant information}

This study was partially funded by the Regional Registry for Internet Number Resources serving the African Internet Community (Afrinic).

The funders had no role in study design, data collection and analysis, decision to publish, or preparation of the manuscript.

\section{Acknowledgements}

This research was conducted with the support of Baobab medical center in Biriwa (Ghana) and Anomabo Health Center (Ghana) and the related communities. We are thankful to Emma K. Capodaglio for kindly copyedit the paper.
1. Zhang $Y, H u$ G, Zhang L, et al:: A novel testing model for opportunistic screening of pre-diabetes and diabetes among U.S. adults. PLOS One. 2015; 10(3): e0120382.

PubMed Abstract | Publisher Full Text | Free Full Text

2. Deshpande AD, Harris-Hayes M, Schootman M: Epidemiology of diabetes and diabetes-related complications. Phys Ther. 2008; 88(11): 1254-1264. PubMed Abstract | Publisher Full Text | Free Full Text

3. Tabák AG, Herder C, Rathmann W, et al:: Prediabetes: a high-risk state for diabetes development. Lancet. 2012; 379(9833): 2279-2290. PubMed Abstract | Publisher Full Text | Free Full Text

4. Gatimu SM, Milimo BW, Sebastian MS: Prevalence and determinants of diabetes among older adults in Ghana. BMC Public Health. 2016; 16(1): 1174. PubMed Abstract | Publisher Full Text | Free Full Text

5. Akter S, Rahman MM, Abe SK, et al:: Prevalence of diabetes and prediabetes and their risk factors among Bangladeshi adults: a nationwide survey. Bull World Health Organ. 2014; 92(3): 204-13, 213A. PubMed Abstract | Publisher Full Text | Free Full Text

6. Zhang P, Gregg E: Global economic burden of diabetes and its implications. Lancet Diabetes Endocrinol. 2017; 5(6): 404-405. PubMed Abstract | Publisher Full Text

7. Hippisley-Cox J, Coupland C: Diabetes treatments and risk of amputation, blindness, severe kidney failure, hyperglycaemia, and hypoglycaemia: open cohort study in primary care. BMJ. 2016; 352: i1450. PubMed Abstract | Publisher Full Text | Free Full Text

8. Papatheodorou K, Papanas N, Banach M, et al:: Complications of Diabetes 2016. J Diabetes Res. 2016; 2016: 6989453.

PubMed Abstract | Publisher Full Text | Free Full Text

9. Hall V, Thomsen RW, Henriksen O, et al.: Diabetes in Sub Saharan Africa 
1999-2011: epidemiology and public health implications. A systematic review. BMC Public Health. 2011; 11(1): 564.

PubMed Abstract | Publisher Full Text | Free Full Text

10. Wild SH, Roglic G, Green A, et al.: Global prevalence of diabetes: estimates for the year $\mathbf{2 0 0 0}$ and projections for 2030: response to Rathman and Giani. Diabetes care. 2004; 27(10): 2569.

Publisher Full Text

11. International Diabetes Federation, Diabetes Atlas Eighth edition. 2017. Reference Source

12. de Graft Aikins A, Owusu-Dabo E, Agyemang C: Diabetes in Ghana: a review of research on prevalence, experiences and healthcare. Chronic Noncommunicable Diseases in Ghana: Multidisciplinary Perspectives. 2014; 1: 41. Reference Source

13. Amoah AG, Owusu SK, Adjei S: Diabetes in Ghana: a community based prevalence study in Greater Accra. Diabetes Res Clin Pract. 2002; 56(3): 197-205.

PubMed Abstract | Publisher Full Text

14. Buxton C, Hagan JE: A survey of energy drinks consumption practices among student -athletes in Ghana: lessons for developing health education intervention programmes. J Int Soc Sports Nutr. 2012; 9(1): 9 PubMed Abstract | Publisher Full Text | Free Full Text

15. Nyonator FK, Awoonor-Williams JK, Phillips JF, et al:: The Ghana communitybased health planning and services initiative for scaling up service delivery innovation. Health Policy Plan. 2005; 20(1): 25-34. PubMed Abstract | Publisher Full Text

16. Escribano Ferrer B, Hansen KS, Gyapong M, et al:: Cost-effectiveness analysis of the national implementation of integrated community case management and community-based health planning and services in Ghana for the treatment of malaria, diarrhoea and pneumonia. Malar J. 2017; 16(1): 277. PubMed Abstract | Publisher Full Text | Free Full Text

17. Peek ME: Can mHealth Interventions Reduce Health Disparities among Vulnerable Populations? Divers Equal Health Care. 2017; 14(2): 44-45. Publisher Full Text

18. Osborn CY, Mayberry LS, Peek ME, et al:: Recent mHealth and Internet interventions for disadvantaged and vulnerable people with type 2 diabetes: Considerations and recommendations for future research. Diversity in Health and care. (2017), 2014; 14(2): 44-45.

19. Kitsiou S, Paré G, Jaana M, et al:: Effectiveness of mHealth interventions for patients with diabetes: An overview of systematic reviews. PLOS One. 2017 12(3): e0173160

PubMed Abstract | Publisher Full Text | Free Full Text

20. Hall AK, Cole-Lewis H, Bernhardt JM: Mobile text messaging for health: a systematic review of reviews. Annu Rev Public Health. 2015; 36: 393-415. PubMed Abstract | Publisher Full Text | Free Full Text

21. Baron J, McBain $\mathrm{H}$, Newman S: The impact of mobile monitoring technologies on glycosylated hemoglobin in diabetes: a systematic review. J Diabetes Sci Technol. 2012; 6(5): 1185-96.

PubMed Abstract | Publisher Full Text | Free Full Text
22. Amoah B, Anto EA, Osei PK, et al.: Boosting antenatal care attendance and number of hospital deliveries among pregnant women in rural communities: a community initiative in Ghana based on mobile phones applications and portable ultrasound scans. BMC Pregnancy Childbirth. 2016; 16(1): 141. PubMed Abstract | Publisher Full Text | Free Full Text

23. Crimi A: DiabetesUP: Initial repository of data related to Nyarko et al. (Version v1.0). Zenodo. 2019 http://www.doi.org/10.5281/zenodo.2587117

24. Mhila G, DeRenzi B, Mushi C, et al.: Using mobile applications for communitybased social support for chronic patients. Health Informatics in Africa. 2009. Reference Source

25. Crowther CA, Hiller JE, Moss JR, et al:: Effect of treatment of gestational diabetes mellitus on pregnancy outcomes. N Engl J Med. 2005; 352(24): 2477-2486. PubMed Abstract | Publisher Full Text

26. World Health Organization: Definition and diagnosis of diabetes mellitus and intermediate hyperglycemia: report of a WHO/IDF consultation. World Hearth Org. 2006. Reference Source

27. Cook-Huynh M, Ansong D, Steckelberg RC, et al:: Prevalence of hypertension and diabetes mellitus in adults from a rural community in Ghana. Ethn Dis. 2012; 22(3): 347-52 PubMed Abstract

28. Mash R, Kroukamp R, Gaziano T, et al.: Cost-effectiveness of a diabetes group education program delivered by health promoters with a guiding style in underserved communities in Cape Town, South Africa. Patient Educ Couns. 2015; 98(5): 622-626.

PubMed Abstract | Publisher Full Text

29. Mwangome M, Geubbels E, Klatser P, et al:: Perceptions on diabetes care provision among health providers in rural Tanzania: a qualitative study. Health Policy Plan. 2017; 32(3): 418-429.

PubMed Abstract | Publisher Full Text | Free Full Text

30. Ganle JK: Ethnic disparities in utilisation of maternal health care services in Ghana: evidence from the 2007 Ghana Maternal Health Survey. Ethn Health. 2016; 21(1): 85-101.

PubMed Abstract | Publisher Full Text

31. Kotler $P$, Zaltman $G$ : Social marketing: an approach to planned social change. J Mark. 1971; 35(3): 3-12.

PubMed Abstract | Publisher Full Text

32. Global physical activity questionnaire: Department of chronic diseases and Health promotion surveillance and population based prevention. World Health Organization, Geneva, Switzerland. Reference Source

33. Asongu SA, Le Roux S: Enhancing ICT for inclusive human development in Sub-Saharan Africa. Technol Forecast Soc Change. 2017; 118: 44-54. Publisher Full Text

34. Cafazzo JA, Casselman M, Hamming N, et al.: Design of an mHealth app for the self-management of adolescent type 1 diabetes: a pilot study. $J$ Med Internet Res. 2012; 14(3): e70.

PubMed Abstract | Publisher Full Text | Free Full Text 


\section{Open Peer Review}

\section{Current Peer Review Status: ? $\mathrm{X}$}

\section{Version 1}

Reviewer Report 01 July 2019

https://doi.org/10.5256/f1000research.20239.r50381

(C) 2019 Schelp F. This is an open access peer review report distributed under the terms of the Creative Commons Attribution License, which permits unrestricted use, distribution, and reproduction in any medium, provided the original work is properly cited.

\section{Frank Peter Schelp}

Faculty of Public Health, Khon Kaen University, Khon Kaen, Thailand

From a historical point it is of interest, that this publication is submitted from authors from Ghana. That is remarkable, as the topic deals with diabetes mellitus, a disease, mainly due to overnutrition and obesity, from a country, where Cecily Delphine Williams once worked and published in 1935 the key paper about 'Kwashiorkor', one of the most severe and deadly conditions due to undernutrition. This reflects the drastic change of public health problems over time, due to the 'epidemiological transition'.

The manuscript is also remarkable, in that it shows how possibly a community approach, might help to control diabetes mellitus. This is within the spirit of 'primary health care', applied to a noncommunicable disease.

The authors report how community health nurses, equipped with inexpensive, appropriate technical innovations, measure capillary blood glucose, assess the BMI, blood pressure and collect information about additional diseases. For the study qualitative and quantitative research methods were applied. The authors repeatedly point out, that one of the major intentions of the project was to study the possibility and feasibility of using community health nurses for working against diabetes mellitus. The paper, with major improvements, will be acceptable as far as solely the qualitative approach is followed in trying to meet the objective. From the point of view of epidemiology however, the quantitative approach is inadequate. To use the term 'screening' is seriously misleading (please see page 257 and 259 of Porta, $2014^{1}$ ). To 'introduce a piloted bias' is an innovative euphemism by the authors and it seems, that they have their own doubts about a meaningful quantitative assessment based on groups of participants being too small and too heterogeneous.

The authors might consider to change the now misleading title, to one which hints towards the objective of the publication more clearly.

The last paragraph of the introduction should be revised and should mention the aims of conducting some sort of quality study. 
The methods and results sections might be combined. More inside information about the communities would be of benefit. Briefly mentioning the assumed knowledge of the participants about diabetes and the attitude towards the disease could help to estimate the usefulness of intervention. A short explanation how the community health worker fit into the overall health care for communities at the periphery of the overall health care system would be worthwhile as well. The section could be structured along the methods applied and for each method the usefulness, the acceptance of the participants within the communities, and the experience of the field worker could be described.

In the discussion the overall experience gained of the project should be summarized in view of how an attempt to control diabetes mellitus in the communities in screening for new cases and caring for diseased patients would be helpful for further investigations and will be informative for local as well as national health workers and administrators. Additional points of interest would be to briefly mention the general dietary intake of the population and how this relates to overweight and diabetes. Last but not least, the question might be addressed on whether cut-off points for 'normal' and 'not-normal' glucose levels, as suggested internationally, are meaningful for Ghana, and what is the reaction of the authors to the recent suggestion to disregard 'prediabetes' as a diagnosis (see Piller, 2019²).

\section{References}

1. Porta M: A Dictionary of Epidemiology, Sixth Edition. Oxford University Press. 2014. Reference

Source

2. Piller C: Dubious diagnosis.Science. 2019; 363 (6431): 1026-1031 PubMed Abstract | Publisher

Full Text

Is the work clearly and accurately presented and does it cite the current literature? No

Is the study design appropriate and is the work technically sound?

No

Are sufficient details of methods and analysis provided to allow replication by others? Partly

If applicable, is the statistical analysis and its interpretation appropriate? No

Are all the source data underlying the results available to ensure full reproducibility? No

Are the conclusions drawn adequately supported by the results? Partly

Competing Interests: No competing interests were disclosed.

Reviewer Expertise: Public Health, epidemiology, nutrition, NCDs, Infectious diseases, health care 
systems in low- and middle income countries

I confirm that I have read this submission and believe that I have an appropriate level of expertise to state that I do not consider it to be of an acceptable scientific standard, for reasons outlined above.

Author Response 20 Aug 2019

Alessandro Crimi, African Institute for Mathematical Science, Cape Coast, Ghana

We have listed here our answers starting with an «(A)».

The paper, with major improvements, will be acceptable as far as solely the qualitative approach is followed in trying to meet the objective. From the point of view of epidemiology however, the quantitative approach is inadequate. To use the term 'screening' is seriously misleading (please see page 257 and 259 of Porta, 20141 ). (A) We agree with the reviewer that given our context and sample size the term "detection» could be more suitable.

To 'introduce a piloted bias' is an innovative euphemism by the authors and it seems, that they have their own doubts about a meaningful quantitative assessment based on groups of participants being too small and too heterogeneous. (A) The authors are sure about the approach considering the goal of increasing early detection and we trust that "our introduced piloted bias» for the purpose is sensible. However, we are perfectly aware that due to funding we are using a small sample size; this is reported more strongly in the limitation of the study.

The last paragraph of the introduction should be revised and should mention the aims of conducting some sort of quality study. (A) We agree with the reviewer, and we have softened the part regarding "novel determinants» which is not the main aim of the study.

The methods and results sections might be combined. More inside information about the communities would be of benefit. Briefly mentioning the assumed knowledge of the participants about diabetes and the attitude towards the disease could help to estimate the usefulness of intervention. A short explanation how the community health worker fit into the overall health care for communities at the periphery of the overall health care system would be worthwhile as well. The section could be structured along the methods applied and for each method the usefulness, the acceptance of the participants within the communities, and the experience of the field worker could be described. (A) The idea of merging methods and results could be unproductive, and actually against the comments of the other reviewer which is asking even more structure. The additional information might be useful and we acknowledge that maybe we considered it as obvious. More specifically, the communities in exam are used to interact with community nurses and there is a high level of trust. The population is also generally aware of the importance of early diagnosis, though very often they restrain from it due to the related costs not covered by the normal insurance.

In the discussion the overall experience gained of the project should be summarized in view of how an attempt to control diabetes mellitus in the communities in screening for new cases and caring for diseased patients would be helpful for further investigations and will be informative for local as well as national health workers and administrators. Additional points of interest would be to briefly mention the general 
dietary intake of the population and how this relates to overweight and diabetes. Last but not least, the question might be addressed on whether cut-off points for 'normal' and 'not-normal' glucose levels, as suggested internationally, are meaningful for Ghana, and what is the reaction of the authors to the recent suggestion to disregard 'prediabetes' as a diagnosis (see Piller, 20192).

1. Porta M: A Dictionary of Epidemiology, Sixth Edition. Oxford University Press. 2014.

2. Piller C: Dubious diagnosis.Science. 2019; 363 (6431): 1026-1031

(A) The paper was submitted in early 2018, when the "opinion» of C. Piller was published at the beginning of 2019. We share the concerns in Europe and US about the abuse of medication for pre-diabetes. This is however, out of place especially considering the context of rural Ghana. Nevertheless, we thank the reviewer for pointing this out. We agree that we should avoid medications for pre-diabetes, while we should promote more awareness on inexpensive physical activities as jogging. Most of the points raised by the reviewers can be addressed by further investigation on physical activities and social marketing campaigns on physical activities.

Competing Interests: No competing interests were disclosed.

Reviewer Report 25 June 2019

https://doi.org/10.5256/f1000research.20239.r49360

(c) 2019 Salazar J. This is an open access peer review report distributed under the terms of the Creative Commons Attribution License, which permits unrestricted use, distribution, and reproduction in any medium, provided the original work is properly cited.

\section{Juan Salazar}

Endocrine and Metabolic Diseases Research Center, School of Medicine, University of Zulia, Maracaibo, Venezuela

This is a report by Nyarko et al., who propose a novel screening strategy for diabetes mellitus in a rural population of Ghana, Africa. An aspect of regional epidemiological relevance that could be reproduced in other geographic locations with similar socioeconomic characteristics.

\section{Abstract:}

Introduction: it is not necessary to define prediabetes in this line.

In Methods, it should describe the type of study and sampling. How were those 101 subjects chosen?

In Results, the sentence "The need for further campaigns on alcohol and physical activity has emerged, even in rural areas", must go in Conclusions not in Results.

\section{Introduction:}

It is somewhat extensive, paragraphs 2 and 3 could be more concise, emphasizing the 
justification for the design of this study.

\section{Materials and methods:}

This section is somewhat disorganized, especially at the sample selection section. For this, it would be convenient to divide by subtitles according to the stages of the project, e.g.:

- Study design and sample selection

- Screening phase

- Diabetes subjects selection phase

- Clinical and capilary sugar evaluation

- Definitions

- Data analysis

- Quantitative approach

- Qualitative approach

You must specify what type of sampling was used for both groups analyzed.

Were the questions used by the mobile app validated or standardized, and by what method? There are some standardized questionnaires to assess the risk of diabetes in "healthy" subjects, such as the Diabetes Risk Test (ADA) and FINDRISK test. Why were some of these not used?

\section{Results:}

There are some characteristics that must be specified in a table or figure:

1. In the USP group, how many subjects were prediabetic and diabetic according to the method used?

2. What were the determinants or risk factors most often evidenced in this group?

3. In the CDP group, how many subjects received pharmacological treatment? What were the most commonly used drugs? What were the factors or determinants of risk in control disease?

4. Although some comparisons are described in the text, as a screening study, some characteristics must also be specified in a table or figure to evaluate the proportions comparatively. In table 2 it is important to include the variables related to psychobiological habits, family and personal history of cardiovascular diseases and their risk factors.

\section{Discussion:}

It would also be advisable to organize this section (without the need to place subtitles) to make it easier to read.

What is known about this topic? Especially in your region. Main findings of the study.

What does this study add?

Limitations: Mention in detail in this section.

Is the work clearly and accurately presented and does it cite the current literature? 
Partly

Is the study design appropriate and is the work technically sound?

Partly

Are sufficient details of methods and analysis provided to allow replication by others? Partly

If applicable, is the statistical analysis and its interpretation appropriate?

Yes

Are all the source data underlying the results available to ensure full reproducibility? Yes

Are the conclusions drawn adequately supported by the results?

Partly

Competing Interests: No competing interests were disclosed.

Reviewer Expertise: Internal medicine, Diabetes. Epidemiology, Chronic disease

I confirm that I have read this submission and believe that I have an appropriate level of expertise to confirm that it is of an acceptable scientific standard, however I have significant reservations, as outlined above.

Author Response 20 Aug 2019

Alessandro Crimi, African Institute for Mathematical Science, Cape Coast, Ghana

We have listed here our answers starting with an «(A)».

Abstract:

Introduction: it is not necessary to define prediabetes in this line. (A) We have removed the sentence.

In Methods, it should describe the type of study and sampling. How were those 101 subjects chosen? (A) As we explained later in the paper, subjects were chosen through snowball sampling.

In Results, the sentence "The need for further campaigns on alcohol and physical activity has emerged, even in rural areas", must go in Conclusions not in Results. (A) We agree with the reviewer.

Introduction:

It is somewhat extensive, paragraphs 2 and 3 could be more concise, emphasizing the justification for the design of this study.

(A) We relatively disagree with the reviewer. Paragraph 2 is about Diabetes in low and middle income countries, while Paragraph 3 is about Ghana. We do believe all information reported is currently relevant. Otherwise we ask the reviewer to point out which sentences are not relevant. 


\section{Materials and methods:}

This section is somewhat disorganized, especially at the sample selection section. For this, it would be convenient to divide by subtitles according to the stages of the project, e.g.:

- Study design and sample selection

- Screening phase

- Diabetes subjects selection phase

- Clinical and capilary sugar evaluation

- Definitions

- Data analysis

- Quantitative approach

- Qualitative approach

(A) We have inserted further subtitles suggested by the reviewer and shuffled some sentences to fit the structure.

You must specify what type of sampling was used for both groups analyzed. (A) Snowballing sampling entrusted to the community nurses was used.

Were the questions used by the mobile app validated or standardized, and by what method? There are some standardized questionnaires to assess the risk of diabetes in "healthy" subjects, such as the Diabetes Risk Test (ADA) and FINDRISK test. Why were some of these not used? (A) The authors are aware of existing standardized questionnaires. However, they are relatively simplistic and comprising basic information not specific for the case in exam. Indeed most of the questions of the standardized questionnaires are included in our ad-hoc questionnaire. We envision our questionnaire as an expansion of the standardized questionnaire. Nevertheless, we are including this clarification.

\section{Results:}

There are some characteristics that must be specified in a table or figure:

1. In the USP group, how many subjects were prediabetic and diabetic according to the method used? (A) This is information is already included in the paper. This is even mentioned in the abstract.

2. What were the determinants or risk factors most often evidenced in this group? (A) Unfortunately we have not found novel strong dietary determinants. The existence of relatives with diabetes for the pre-diabetic group is not a novel discovery. Our contribution is that it is possible to perform early detection of diabetes and pre-diabetes and that there is still a general misconception of what "physical activity» is.

3. In the CDP group, how many subjects received pharmacological treatment? What were the most commonly used drugs? What were the factors or determinants of risk in control disease? (A) All subjects in the CDP group were following pharmacological treatment, but we do not know the details of this.

4. Although some comparisons are described in the text, as a screening study, some characteristics must also be specified in a table or figure to evaluate the proportions comparatively. In table 2 it is important to include the variables related to psychobiological habits, family and personal history of cardiovascular diseases and 
their risk factors. (A) We are not in possession of detailed information about cardiovascular diseases apart from hypertension. However, if not reported most likely there is no past medical history of cardiovascular diseases for the subjects in exam. The study focused on the early detection of diabetes and pre-diabetes, we will acknowledge in the discussion section that deeper investigation on cardiovascular disease is missing and represents a limitation.

\section{Discussion:}

It would also be advisable to organize this section (without the need to place subtitles) to make it easier to read.

What is known about this topic? Especially in your region. Main findings of the study.

What does this study add?

Limitations: Mention in detail in this section.

(A) We have restructured the discussion section, particularly adding a paragraph on "what is known» and a paragraph about «limitations».

Competing Interests: No competing interests were disclosed.

The benefits of publishing with F1000Research:

- Your article is published within days, with no editorial bias

- You can publish traditional articles, null/negative results, case reports, data notes and more

- The peer review process is transparent and collaborative

- Your article is indexed in PubMed after passing peer review

- Dedicated customer support at every stage

For pre-submission enquiries, contact research@f1000.com 